\title{
STUDI EKSPERIMEN TEKNOLOGI PEMBANGKIT LISTRIK TENAGA ARUS LAUT (PLTAL) MENGGUNAKAN SAVONIUS BACH ROTOR
}

\author{
Yusiran $^{1, *}$, Erwin $^{2}$ \\ ${ }^{1}$ Mahasiswa Jurusan Fisika, Universitas Riau \\ ${ }^{2}$ Dosen Jurusan Fisika, Universitas Riau \\ *E-mail korespondensi: yusiran123@gmail.com
}

\begin{abstract}
Design and experiment of ocean current power generation system have been carried out using the Bach Savonius rotor. In this research, the influence of the velocity of ocean currents, the number of turbine blades, and the blade arc angle of the generator output power are studied. The results showed that the turbine output power is strongly influenced by the velocity of ocean currents where the velocity values of ocean currents varied in the range 0,63-1,98 $\mathrm{m} / \mathrm{sec}$. The maximum elctrical power of the turbine occurs at a current velocity of 1,98 m/sec of 26,88 Watts. The number of turbine blades has a significant effect on turbine output power. The turbine reaches maximum power is found in the rotor with a number of 3 blades with a power coefficient of 0,1176 on the tip speed ratio of 0,359 . The blade arc angle is varied at angles of $90^{\circ}, 135^{\circ}$ and $165^{\circ}$. The blade arc angle $135^{\circ}$ gives the best performance with a power coefficient of 0,102 on the tip speed ratio of 0,298.
\end{abstract}

Keywords: Blades, Ocean Current, Turbine, Power

\begin{abstract}
ABSTRAK
Telah dilakukan desain dan eksperimen pembangkit listrik tenaga arus laut menggunakan tipe turbin Savonius Bach. Pada penelitian ini dipelajari pengaruh kecepatan arus laut, jumlah bilah turbin, dan sudut busur bilah terhadap daya keluaran pembangkit. Hasil penelitian menunjukkan bahwa daya keluaran turbin sangat dipengaruhi oleh kecepatan arus laut dimana nilai kecepatan arus laut bervariasi dalam rentang 0,63-1,98 $\mathrm{m} / \mathrm{s}$. Daya maksimum turbin terdapat pada kecepatan arus 1,98 m/s sebesar 26,88 Watt. Jumlah bilah turbin memberikan pengaruh terhadap daya keluaran turbin. Turbin yang mencapai daya maksimum terdapat pada rotor dengan jumlah bilah 3 buah dengan nilai koefisien daya 0,11 pada tip speed ratio 0,359. Sudut busur bilah divariasikan pada sudut $90^{\circ}, 135^{\circ}$ dan $165^{\circ}$. Sudut busur bilah $135^{\circ}$ memberikan performa terbaik dengan nilai koefisien daya 0,102 dengan nilai tip speed ratio 0,298.
\end{abstract}

Kata kunci: Bilah, Daya, Arus Laut, Turbin

Diterima 25-6-2019| Disetujui 14-08-2019| Dipublikasi 31-10-2019

\section{PENDAHULUAN}

Energi arus laut adalah salah satu sumber daya energi terbarukan yang menarik untuk dikembangkan karena memiliki beberapa keunggulan, yang dapat diprediksi, terukur, dan tidak memiliki dampak secara visual [1]. Eksplorasi arus laut di dekat pantai bukanlah hal yang baru. Penerapan sumber daya energi arus laut telah dimulai sejak 1966 di Perancis [2]. Proses konversi energi kinetik dari arus laut menjadi energi listrik dapat dilakukan dengan menggunakan turbin arus laut sumbu vertikal dan turbin arus laut sumbu horizontal. Meskipun sumber energi dari arus laut lebih menjanjikan, masalah yang muncul dalam proses penerapan teknologi pembangkit listrik arus laut adalah tingginya biaya pembuatan 
dan pemasangan alat. Penyebab peningkatan biaya pembuatan dan pemasangan alat adalah aksestabilitas yang terbatas dan memerlukan pengerjaan bawah laut. Untuk mengatasi masalah ini, para peneliti telah mengusulkan berbagai konsep. Gorlov merancang turbin heliks yang mampu memanfaatkan energi arus laut dengan kecepatan rendah tanpa konstruksi bendungan. Konsep ini ditawarkan untuk mengurangi kerusakan lingkungan akibat pembangunan bendungan yang merusak ekosistem di wilayah tersebut dan mengurangi biaya pembangkit listrik [3]. Jenis turbin lain yang dikembangkan oleh Marine Current Turbine Ltd adalah turbin Kobold yang dipasang di bawah pelampung. [4]. Penelitian yang disebutkan di atas adalah beberapa upaya praktis untuk mengurangi biaya investasi pembangkit energi arus laut, namun, kendala biaya belum selesai dengan pengembangan kedua jenis turbin Gorlov dan Kobold, alasannya adalah bahwa proses pembuatan turbin rumit dan masih membutuhkan biaya yang cukup banyak.

Terdapat satu jenis turbin yang mudah dibuat, lebih murah dan dapat bekerja pada kecepatan aliran fluida rendah, disebut turbin Savonius. Turbin Savonius biasanya terdiri dari dua bilah melengkung dengan alur aliran yang mengelilingi pusat. Dalam desain aslinya, setiap bilah memperlihatkan bentuk setengah lingkaran [5]. Turbin Savonius masih memiliki kekurangan, efisiensi turbin masih sangat rendah. Para peneliti berusaha untuk memperbaiki kelemahan ini dengan mengoptimalkan parameter turbin. Hanya sedikit peneliti yang menggunakan turbin Savonius Konvensional untuk diaplikasikan sebagai turbin aliran air. Hassanzadeh melakukan penelitian eksperimental untuk membuat konfigurasi baru turbin arus laut menggunakan turbin Savonius Konvensional [6].

Upaya untuk memperoleh peningkatan kinerja yang signifikan, penulis bekerja untuk merancang dan melakukan studi eksperimental pembangkit listrik turbin Savonius menggunakan rotor Bach Savonius dan mempelajari pengaruh jumlah bilah turbin dan sudut lengkung pisau terhadap kinerja sistem pembangkit listrik. Percobaan ini dirancang untuk memungkinkan pengukuran kecepatan arus laut dan variabel operasional untuk menentukan output daya listrik, koefisien kinerja dan torsi dinamis.

\section{TINJAUAN PUSTAKA}

Bach adalah salah satu profil umum kedua yang digunakan dalam rotor Savonius yang diajukan oleh Bach enam tahun setelah profil konvensional. Bach menggantikan profil setengah lingkaran dengan profil Bach yang terdiri dari garis lurus dan busur. Gambar 1 menunjukkan geometri rotor Savonius Bach.

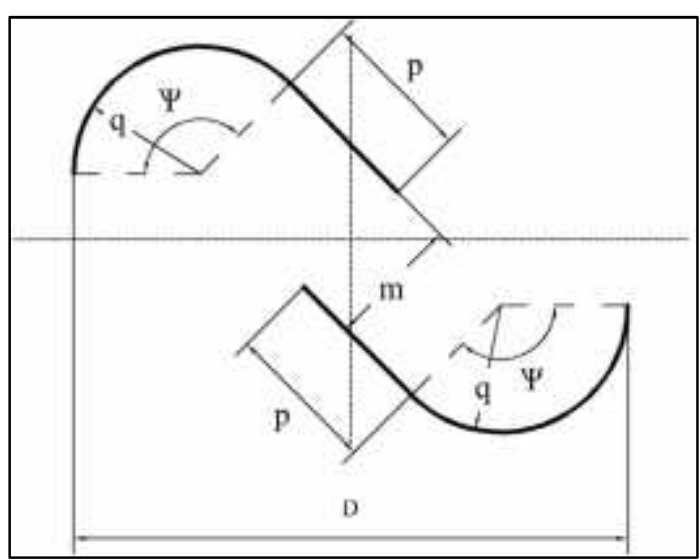

Gambar 1. Geometri rotor Savonius Bach.

Pada penelitian turbin angin, studi perbandingan rotor Savonius Bach dan Savonius konvensional telah dilakukan. Hasil penelitian menunjukkan bahwa Bach Rotor mencapai kinerja yang lebih baik daripada turbin Savonius Konvensional [6].Daya yang dihasilkan oleh arus laut dihitung menggunakan Persamaan 1 [7].

$$
r_{T}=\frac{1}{2} \rho \quad v_{T}^{3}
$$

$P_{T}$ adalah daya yang dihasilkan oleh arus laut, $\rho$ adalah densitas air laut $\left(1.025 \mathrm{~kg} / \mathrm{m}^{3}\right), A$ adalah area sapuan dan $V_{T}$ adalah kecepatan arus laut $(\mathrm{m} / \mathrm{s})$. Daya yang diekstraksi oleh turbin Savonius dari aliran bebas air laut dapat dihitung dengan menggunakan Persamaan 2 [8].

$$
P_{M}=T \cdot \omega
$$


dimana $T$ adalah torsi $(\mathrm{N}-\mathrm{m})$ yang dihasilkan oleh turbin dan $\omega$ adalah kecepatan rotasi $(\mathrm{rad} / \mathrm{s})$ dari turbin. Upaya untuk mengevaluasi berapa banyak energi yang digunakan oleh turbin dari aliran aliran bebas, istilah TSR didefinisikan. Ini menghubungkan kecepatan aliran bebas dengan kecepatan di ujung pisau dan dinyatakan dalam Persamaan 3 [9].

$$
T=\frac{\omega . K}{V_{T}}
$$

Kinerja turbin dinyatakan dengan besaran non-dimensional dengan menggunakan istilah koefisien daya $C p$ yang didefinisikan sebagai rasio daya yang diekstraksi oleh turbin, $P_{M}$ terhadap daya yang dihasilkan oleh arus laut $H_{T}$, dinyatakan dalam Persamaan 4.

$$
C=\frac{P_{M}}{P_{T}}
$$

\section{METODE PENELITIAN}

Suatu studi eksperimen dilakukan untuk menguji model sistem pembangkit listrik tenaga arus laut di lingkungan perairan Selat Rupat. Kecepatan arus laut diukur menggunakan currentmeter. Kecepatan putaran rotor pada kecepatan arus laut tertentu diukur menggunakan tachometer laser digital. Generator DC digunakan untuk menentukan output daya listrik dan torsi dinamis. Upaya untuk mengukur arus listrik dilakukan dengan menggunakan multimeter dan resistor 20-ohm dihubungkan untuk menentukan arus keluaran maksimum.

Bilah model rotor Bach dibuat dari lembaran alumunium setebal $2 \mathrm{~mm}$ karena kemampuan kinerja yang baik. Untuk menekuk lembaran alumunium untuk merancang profil menggunakan mesin pelengkung. Percobaan menggunakan rotor Bach Savonius dengan 2, 3 dan 4 bilah. Sudut busur bilah untuk menyelidiki kinerja Bachrotor dengan berbagai jumlah blade adalah $135^{\circ}$. Sudut busur blade bervariasi dalam sudut $90^{\circ}, 135^{\circ}$ dan $165^{\circ}$ dengan jumlah blade yang ditetapkan dua bilah.
Perancangan dan eksperimen pembangkit listrik tenaga arus laut telah berhasil dilakukan. Prototipe pembangkit listrik tenaga arus laut dengan turbin tipe Savonius Bach yang telah dibuat dan diuji coba ditunjukkan pada Gambar 2.

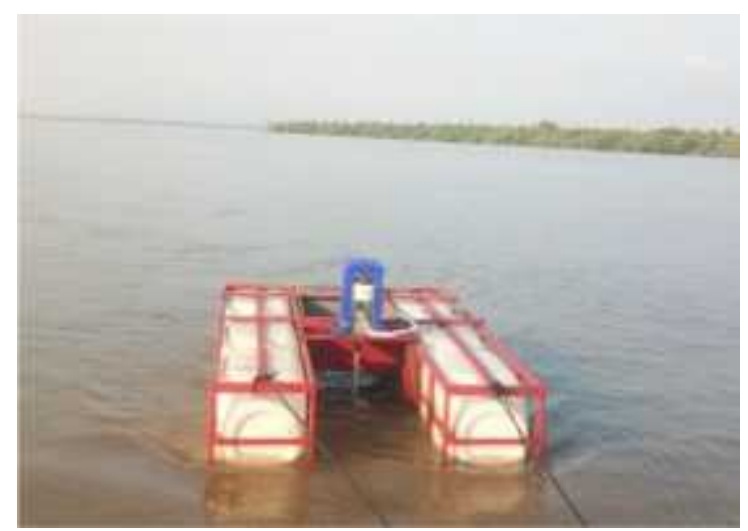

Gambar 2.Pengujian prototipe di Selat Rupat

Pengukuran kecepatan arus laut menggunakan current meter dilakukan setiap 30 menit. Pengukuran kinerja untuk masingmasing turbin dikerjakan selama 4 jam 30 menit ( 1 kali periode pasang air laut). Pada saat pergantian pola arus dari pasang naik ke pasang surut atau sebaliknya dilakukan penggantian turbin namun tetap dilakukan pengukuran kecepatan arus laut. Grafik daya listrik terhadap kecepatan arus laut diperlihatkan pada Gambar 3.

Gambar 3 menunjukkan bahwa pada kecepatan arus laut $0,63 \mathrm{~m} / \mathrm{s}$ daya yang dihasilkan oleh turbin arus laut bernilai 1,95 Watt dengan nilai tegangan 7,82 Volt dan arus listrik 0,25 A. Kecepatan arus maksimum saat pasang naik adalah $1,98 \mathrm{~m} / \mathrm{s}$, dan daya yang dihasilkan sebesar 26,88 Watt. Hasil ini menunjukkan bahwa peningkatan daya sebanding dengan peningkatan arus laut. Berdasarkan Persamaan 1 maka daya turbin sebanding dengan kecepatan arus laut kubik $\left(\mu \propto v^{3}\right)$ sehingga daya keluaran turbin sangat dipengaruhi oleh kecepatan arus laut.

\section{HASIL DAN PEMBAHASAN}




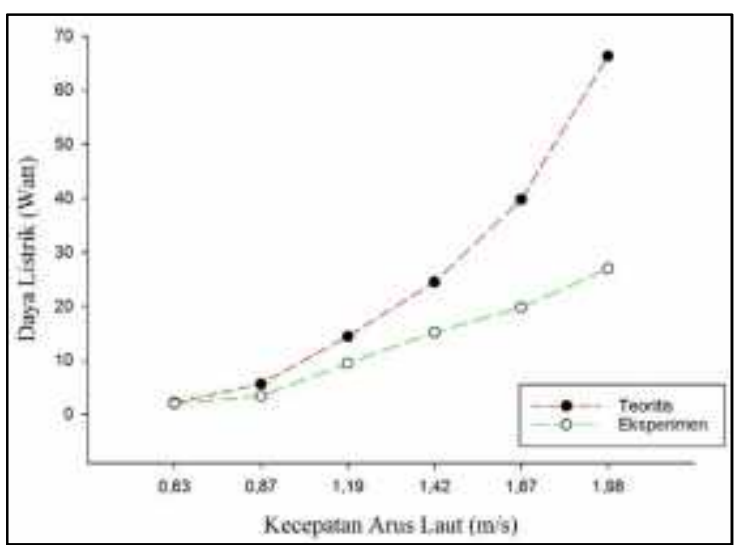

Gambar 3.Grafik hubungan daya listrik terhadap kecepatan arus laut.

Penelitian ini juga mempelajari pengaruh kecepatan arus laut terhadap kecepatan putaran turbin. Hasil pengukuran kecepatan putaran turbin terhadap kecepatan arus laut dapat dilihat dalam grafik pada Gambar 4.

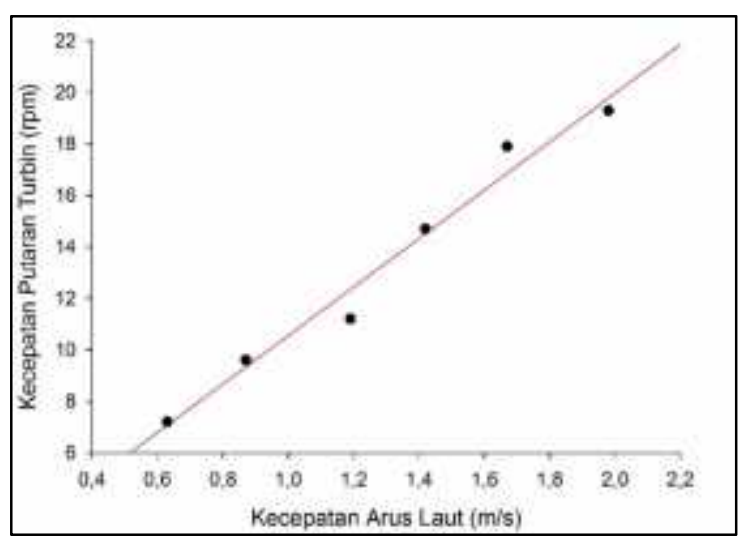

Gambar 4. Hubungan kecepatan putaran turbin terhadap kecepatan arus laut.

Gambar 4 memperlihatkan bahwa pada kecepatan arus minimum $0,63 \mathrm{~m} / \mathrm{s}$ kecepatan putaran turbin hanya $7,2 \mathrm{rpm}$ kemudian meningkat menjadi 19,8 rpm pada kecepatan arus laut $1,98 \mathrm{~m} / \mathrm{s}$, sehingga kecepatan putaran turbin hanya terdapat pada rentang nilai 7-20 rpm, yang berarti turbin arus laut hanya berotasi lambat (low speed rpm). Penyebab dari rendahnya tingkat putaran turbin adalah besarnya densitas air laut yaitu sebesar 1.025 $\mathrm{kg} / \mathrm{m}^{3}$ dan sangat jauh berbeda dengan turbin angin yang mampu berotasi sangat cepat dikarenakan densitasnya yang rendah. Besarnya densitas air laut 830 kali lebih besar dari densitas udara.
Pengaruh jumlah bilah turbin terhadap kinerja pembangkit listrik tenaga arus laut dipelajari pada penelitian ini. Grafik daya listrik yang dihasilkan oleh variasi jumlah bilah ditampilkan pada Gambar 5 .

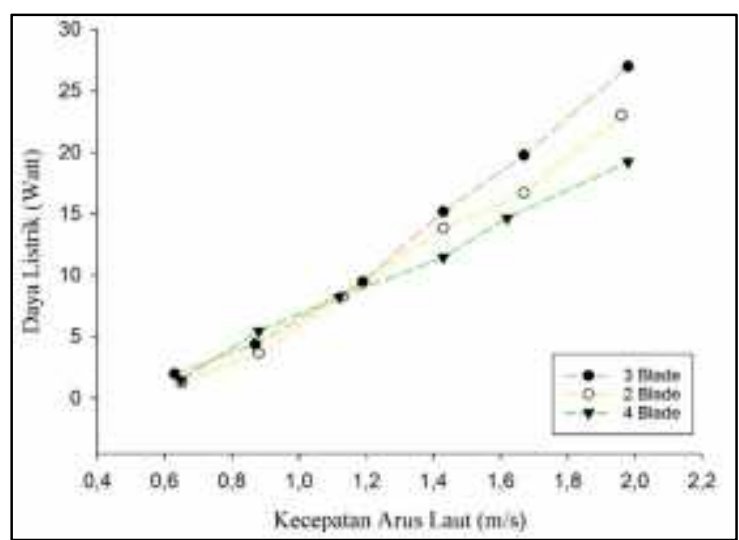

Gambar 5. Grafik daya turbin terhadap kecepatan arus laut untuk variasi jumlah bilah turbin.

Berdasarkan Gambar 5, dapat diketahui bahwa turbin dengan jumlah 3 blade menghasilkan daya yang paling tinggi dibandingkan turbin dengan jumlah bilah turbin 2 dan 4 . Turbin dengan jumlah 3 blade mampu menghasilkan daya 26,88 Watt pada kecepatan arus maksimum, sedangkan turbin dengan jumlah blade 2 dan 4 masing-masing menghasilkan daya maksimum 23,01 Watt dan 19,09 Watt.

Pada turbin dengan 3 blade, kesenjangan yang jauh antar bilah menyebabkan air mengalir bebas dan mengenai bilah yang lainnya oleh karena itu menghasilkan gaya dorong positif. Penambahan jumlah blade menyebabkan gaya hambat saat sisi cembung bilah bergerak mundur (returning blade) mengakibatkan munculnya torsi negatif yang melawan torsi positif sehingga menyebabkan putaran turbin tidak optimal.Upaya untuk membandingkan kinerja masing-masing turbin, dapat dilakukan dengan membandingkan nilai koefisien daya serta torsi dinamis yang dihasilkan oleh turbin. Hasil perhitungan nilai koefisien daya, torsi dinamis dan TSR ditampilkan pada Tabel 1. 
Tabel 1. Hasil perhitungan torsi dinamis, TSR, dan koefisien daya turbin dengan variasi jumlah bilah.

\begin{tabular}{cccc}
\hline $\begin{array}{c}\text { Jumlah } \\
\text { Bilah }\end{array}$ & $\begin{array}{c}\text { Torsi Dinamis } \\
(\mathrm{N}-\mathrm{m})\end{array}$ & TSR & $C p$ \\
\hline 2 & 33,25 & 0,325 & 0,1073 \\
3 & 33,68 & 0,359 & 0,1176 \\
4 & 29,43 & 0,281 & 0,0668 \\
\hline
\end{tabular}

Tabel 1 menginformasikan bahwa pada kecepatan arus laut $1,42 \mathrm{~m} / \mathrm{s}$ nilai koefisien daya tertinggi terdapat pada turbin dengan rotor 3 bilah yaitu sebesar 0,1176 , sedangkan pada rotor dengan 2 bilah memiliki nilai $C p$ 0,1073 dan rotor dengan 4 bilah memiliki nilai koefisien daya paling rendah yaitu 0,0668 . Berdasarkan perbedaan nilai $C p$ tersebut dapat diketahui bahwa turbin kinerja turbin terbaik terdapat pada rotor dengan 3 bilah. Turbin dengan 2 bilah hanya mampu mengkonversi $10 \%$ dari daya yang dihasilkan arus laut. Kinerja turbin semakin memburuk saat penambahan bilah, terlihat pada turbin dengan 4 bilah hanya mampu mengubah daya arus laut menjadi daya listrik sebesar $6 \%$ pada kecepatan arus laut $1,42 \mathrm{~m} / \mathrm{s}$.

Pengaruh sudut busur bilah (blade arc angle) terhadap daya keluaran turbin dapat dipelajari dalam grafik pada Gambar 6.

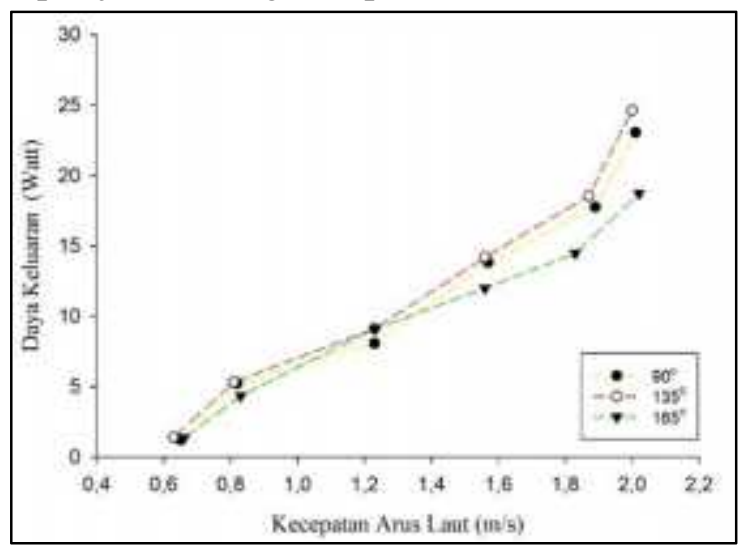

Gambar 6 Grafik daya turbin terhadap kecepatan arus laut dengan variasi sudut busur bilah turbin (blade arc angle)

Gambar 5 menunjukkan bahwa pada kecepatan maksimum $2,0 \mathrm{~m} / \mathrm{s}$ (saat air laut dalam keadaan pasang surut) bilah turbin dengan sudut busur $90^{\circ}$ menghasilkan daya maksimum 19,90 Watt dan pada bilah dengan sudut busur $165^{\circ}$ menghasilkan daya maksimum 18,72 Watt, sedangkan turbin dengan sudut busur bilah $135^{\circ}$ menghasilkan daya maksimum 23,06 Watt. Daya tertinggi dicapai oleh turbin dengan sudut busur bilah $135^{\circ}$. Grafik pada Gambar 4.9 juga menginformasikan bahwa sudut busur bilah $90^{\circ}, 135^{\circ}$ dan $165^{\circ}$ Berdasarkan hasil penelitian dapat diketahui bahwa peningkatan sudut busur bilah (blade arc angle) tidak berbanding lurus dengan peningkatan daya listrik yang dihasilkan turbin, dimana turbin menunjukkan nilai optimal pada sudut busur tertentu.

\section{KESIMPULAN}

Berdasarkan hasil penelitian yang telah dilakukan dapat disimpulkan bahwa Daya keluaran pembangkit listrik dengan tipe turbin Savonius Bach sangat dipengaruhi oleh kecepatan arus laut. Daya maksimum yang dihasilkan oleh PLTAL sebesar 26,88 Watt pada kecepatan arus maksimum saat pasang naik $1,98 \mathrm{~m} / \mathrm{s}$. Jumlah bilah turbin mempengaruhi daya keluaran turbin. Jumlah bilah dengan koefisien daya tertinggi terdapat pada rotor tubin 3 bilah dengan nilai 0,11 pada tip speed ratio 0,359 . Sudut busur bilah (blade arc angle) memberikan pengaruh terhadap kinerja turbin. Sudut busur bilah memberikan performa terbaik terdapat pada nilai $135^{\circ}$ yang mampu mencapai daya maksimum 23,06 Watt dan nilai koefisien daya maksimum 0,102 pada nilai tip speed ratio 0,298 .

\section{REFERENSI}

1. Vennell, S. W., Funke, S., Draper, C., Stevens, \& Divett, T. (2015). Designing large arrays of tidal turbines: a synthesis and review. Renewable and Sustainable Energy Reviews, 41 (5),454-472.

2. Kamoji, M. Kedare, S, Prabhu, S. (2009). Performance Test on Helical Savonius Rotors. Renewable Energy, 34(3), 521-529.

3. Gorlov, A. M. (1998). Helical turbines fot the Gulf Stream: Conceptual approach design of a large- scale floating power farm.Marine Technology, 35(1), 175-177. 
4. Mauller, G. \& Kauppert, K. (2004). Performance characteristic of water wheels. Journal of Hydraulic Research, 42 (5), 1-6.

5. Akimoto, H., Tanaka, K.., \& Uzawa J (2013). A conceptual study of floating axis water current turbine for low-cost energy capturing from river, tide and ocean current Renewable Energy 57(1), 283-288.

6. Hassanzadeh, R., Yaakob, U., Gholami, A., Pourmahdavi, M, Hoissenzadeh, M., Taheri M. M. \& Ahmed, Y. (2018). Experimental investigation of an innovative configuration for new marine current turbine.Renewable Energy, 18 (1), 92-93.
7. Khan, M. J., Iqbal, M. T. \& Quiacoe, J. E. (2008). River current energy conversion system: Progress, prospects and challenges Renewable Sustain Energy Reviews,8(3), 21772179.

8. Bhayo, B. \& Kayiem. (2017). Experimental Characterization and Comparison of Performance of S-Rotor for Standalone Wind Power System. Journal of Energy. 138 (2), 752763.

9. Wu, H. N., Chen, L. J., Ming, H. Y., Li, W. Y. \& Chen, B. F., (2012). On design and performance prediction of the horizontal-axis water turbine. Ocean Engineering, 50(1), 23-30. 